\title{
A ética na pesquisa etnográfica com crianças: primeiras problematizações ${ }^{*}$
}

\author{
Ethics in ethnographic research with children: first \\ problematizations
}

\section{La ética en la investigación etnográfica con niños: primeras problematizaciones}

\author{
Maria Carmen Silveira Barbosa ${ }^{* *}$
}

\begin{abstract}
Resumo: Este artigo problematiza a questão da ética na pesquisa com crianças. Essa discussão tornou-se fundamental, pois muitos trabalhos da sociologia da infância, da antropologia das crianças e da investigação pedagógica têm como fundamento a etnografia. No Brasil, as crianças são consideradas pessoas vulneráveis. Assim, todas as pesquisas com crianças precisam de aprovação prévia dos comitês de ética, encontrando problemas para serem aprovadas, pois tencionam a legislação em três aspectos: conceito de criança basicamente vulnerável, esquecendo-se das possibilidades de participação e de protagonismo dela; questão do método etnográfico, pois se exige uma metodologia definida antes da entrada em campo; restrições à captura e à divulgação de imagens e de produtos realizados por crianças. Essas tenções precisam ser discutidas para ser construída uma ética não apenas para as pesquisas realizadas nas ou sobre as crianças, mas, principalmente, com e para as crianças, que possa proteger e afirmar as capacidades delas como sujeitos de direto.
\end{abstract}

Palavras chave: Ética na pesquisa. Infância. Pesquisa.

\begin{abstract}
This article discusses the issue of ethics in ethnographic research with children. This discussion has become crucial because many works in the field of childhood sociology, anthropology of children and educational research is based on the ethnographic research. In Brazil, children are considered vulnerable people. Thus, all research with children need prior approval from ethic committees, finding problems to be approved, as it involves the legislation in three aspects: the concept of basically vulnerable child, forgetting the possibilities of children's participation and protagonism; the issue of the ethnographic method, as it is required a fully defined methodology before entering the field; and restrictions to the capture and the dissemination of
\end{abstract}

\footnotetext{
* Este texto é uma síntese da conferência de abertura do III Seminário de Grupos de Pesquisa sobre crianças e infâncias: políticas e desafios na produção da pesquisa (22 a 24 de agosto de 2012) - Aracajú, Sergipe.

** Professora da Faculdade de Educação da Universidade Federal do Rio Grande do Sul. E-mail: <licabarbosa@ ufrgs.br>
} 
images and products made by the children. These issues need to be discussed so that ethic is built not only for researches on and about the children, but, mainly, with and for the children, that can protect and also affirm their capacity as subjects with rights.

Keywords: Ethics in research. Childhood. Research.

Resumen: Este artículo problematiza la cuestión de la ética en la investigación con niños. Esa discusión es fundamental ya que muchos trabajos tanto de sociología y de antropología de la infancia como de la investigación pedagógica utilizan a la etnografía como fundamento. En Brasil, los niños-as son considerados personas vulnerables. De esta forma, todas las investigaciones con niños-as precisan una aprobación previa de los comités de ética, encontrando dificultades para que sean aprobados porque tensionan a la legislación en tres aspectos: el concepto de niño-a como básicamente vulnerable, olvidándose de sus posibilidades de participación y de protagonismo; la cuestión del método etnográfico que exige una metodología definida antes de entrar en campo; restricciones a la captura y a la divulgación de imágenes y de productos realizados por los niños-as. Esas tensiones precisan ser discutidas para ser construida una ética no apenas para las investigaciones realizadas en o sobre los niños-as, sino principalmente, con y para los niños-as, que pueda proteger y afirmar las capacidades de los mismos como sujetos de derecho.

Palabras claves: Ética en la investigación. Infancia. Investigación.

\section{Introdução}

A construção de princípios éticos para a investigação científica foi um importante avanço no sentido de que as sociedades pudessem continuar realizando pesquisas, tendo o cuidado de proteger os cidadãos que fazem parte dos grupos investigados e definindo, socialmente, parâmetros para os indivíduos e as instituições de pesquisa. Afinal toda a ação humana é social e exige ética em seus princípios e em seus procedimentos. A questão central deste artigo é problematizar três aspectos que têm dificultado a solicitação e a aprovação de projetos de pesquisa qualitativa nos comitês de ética em pesquisa, especialmente aqueles com base etnográfica, com meninos e meninas.

O primeiro aspecto diz respeito ao conceito de ciência, pois a proposta da etnografia como metodologia de pesquisa aberta e interativa, cujas decisões são tomadas ao longo do processo de pesquisa, nao é compatível com a avaliação prévia de um projeto que desde o início já está definido. O segundo é o fato de que a pesquisa com crianças exige dos comitês uma imagem mais contemporânea dessas crianças - crianças como sujeitos com direitos, com protagonismo 
e ação social. Por fim, o terceiro aspecto, derivado do anterior, é a questão da capacidade de as crianças participar das investigações e ter, quando necessário, direito à publicação de suas imagens, seus nomes e suas contribuições intelectuais. O posicionamento ético e político do pesquisador não passa apenas por atender prontamente às definições e às regras dos códigos padrões ${ }^{1}$, mas passa, principalmente nesse momento inicial de discussão pública sobre a pesquisa em ciências humanas e sociais, por observar práticas, formular perguntas e propiciar caminhos para estabelecer uma visão plural e contextualizada da ética.

\section{Metodologia de pesquisa}

A base empírica desta pesquisa são artigos publicados em periódicos nacionais, como nos Cadernos de Pesquisa, número 31, de dezembro de 1979, e número 116, de julho de 2002, da Fundação Carlos Chagas, e a literatura internacional sobre pesquisa com crianças, especialmente três publicações: Christensen e James (2000), Graue, Walsh e Chaves (2003), Qvortrup, Corsaro e Honig (2011), Lange e Mierendorff (2011), Mortari (2007, 2009) e, também, a experiência da pesquisadora e orientadora de estágios, trabalhos de conclusão de cursos, dissertações e teses e membro de uma Comissão de Pesquisa.

\section{Sobre ética em pesquisa com crianças}

Após a Segunda Guerra Mundial, as discussões sobre ética em pesquisa, envolvendo seres humanos, obteve centralidade no campo científico, pois o ocidente vivia o luto das atrocidades cometidas em nome da ciência nos campos de concentração (Código de Nuremberg, 1947). A área de estudos da saúde, especialmente os estudos sobre medicações com seus modelos de tratamento invasivos, empreenderam um código de ética para a investigação científica a partir do marco da legislação internacional (Declaração de Helsinque, 1964). Esse documento foi submetido a constantes revisões ${ }^{2}$ e, ainda hoje, é uma referência nos aspectos éticos que devem nortear a investigação bioética. Esse início ligado aos estudos de saúde fez com que grande parte da discussão sobre a ética na pesquisa tivesse como matriz o tema da vida e a possibilidade de sua perda e uma visão de pesquisa com parâmetros muito específicos: experimental, quantitativa e biomédica. Desde as primeiras normativas, as crianças foram colocadas

\footnotetext{
${ }^{1}$ É possível, a partir de definições filosóficas, questionar se estes são códigos de ética ou códigos morais. Pensa-se que os códigos são morais, pois seres humanos que somos possuímos muitas dúvidas e queremos que a moral ofereça todas as respostas e as garantias, mas as comissões têm, fundamentalmente, a função de pensar eticamente, caso a caso, a partir de critérios abertos a diversidade.

2 Tokio, 1975; Veneza, 1983; Hong Kong, 1989; Somerset West, 1996; Edinburgo, 2000; Washington, 2002; Helsinki, 2004.
} 
como integrantes dos grupos especiais, porém, em 1983, foi discutida e incluída a perspectiva de buscar, sempre que possível, o consentimento das crianças e dos adolescentes e não apenas dos adultos responsáveis.

Em 1993, as Diretrizes Internacionais Ética para a Investigação Envolvendo Seres Humanos, do Council for International Organizations of Medical Sciences (CIOMS), em colaboração com a Organização Mundial da Saúde (OMS), afirmaram que a investigação com crianças e jovens somente deve ser feita quando não for possível fazê-las com os adultos, que os pais ou os responsáveis legais devem dar consentimento, que o consentimento de cada criança deve ser obtido na medida de sua capacidade e que a recusa da criança para participar em uma pesquisa deve ser sempre respeitada. Assim, pouco a pouco, as crianças foram ocupando espaços nos códigos de ética em pesquisa.

Por outro lado, a pesquisa etnográfica sempre teve as crianças como informantes, mas nem sempre elas foram consideradas como sujeitos confiáveis. A literatura acadêmica, especialmente a da antropologia indígena (SILVA; MACEDO; NUNES, 2000, p. 17), afirma que as crianças são ótimas interlocutoras e, muitas vezes, são os primeiros contatos dos pesquisadores, visto que se sentem curiosas e servem como guias na aldeia, pois transitam com muita liberdade entre os diferentes núcleos sociais. Contudo, em geral, há pouca pesquisa sobre como os investigadores encontraram as crianças, como se aproximaram, conversaram e a sua importância na vida coletiva de seu grupo. Isto é, apesar de as crianças participarem das pesquisas, por muito tempo, não foram objeto de investigação.

\section{Ética na pesquisa no Brasil}

Em 1996, seguindo as determinações internacionais sobre a necessidade de padrões éticos em pesquisa, a Comissão Nacional de Saúde, no Brasil, tornou obrigatória, por meio da Resolução 196/96 do Conselho Nacional de Saúde ${ }^{3}$, a análise ética de toda a pesquisa com pessoas vulneráveis ${ }^{4}$. Essa legislação teve por objetivo contemplar os princípios bioéticos da autonomia, da beneficência, da não maleficência, da justiça, da confidencialidade, da privacidade, da voluntariedade, da equidade e da não-estigmatização, os quais têm sido amplamente utilizados no contexto da prática de pesquisa internacional. Esses preceitos funcionam como

\footnotetext{
${ }^{3}$ Resolução 196/96, Diretrizes e Normas regulamentadoras de Investigação Envolvendo Seres Humanos. Disponível em: <http://www.bioetica.ufrgs.br/res19696.htm>. A Resolução 196/96 foi revogada pela aprovação, pelo Conselho Nacional de Saúde, da Resolução 466/2012, de 12 de dezembro de 2012.

${ }^{4}$ A distinção entre autonomia reduzida é uma condição individual, transitória, como a das crianças e a vulnerabilidade que existe por condições sociais, culturais, étnicas, políticas, econômicas, educacionais ou de saúde em que as diferenças estão colocadas como desigualdade. Disponível em: <http://www.ufrgs.br/bioetica/ vulnera.htm>. Acesso em: 8 ago. 2012.
} 
salvaguarda para a proteção dos sujeitos das pesquisas, mas também servem para garantir a segurança dos investigadores, das empresas financiadoras e das instituições de investigação.

Como as crianças e os jovens são considerados pessoas vulneráveis, todas as pesquisas feitas com crianças necessitam aprovação prévia nos Comitês de Ética na Pesquisa (CEP). A questão central que enfrentamos, no Brasil, é que esses comitês ainda são poucos e, em geral, estão organizados em universidades e hospitais, analisando, preponderantemente, investigação sobre questões de saúde e têm como referência científica as pesquisas quantitativas. Isso faz com que a pesquisa etnográfica, realizada com as crianças, encontre problemas para a sua aprovação, pois muito do que é exigido desde os prontuários oficiais para apresentação dos projetos já necessita especificações que são inadequadas a uma pesquisa processual. Assim, o comitê afirma não se sentir suficientemente informado para aprovar o projeto ou, ainda, o analisa como incompleto.

Como afirmam Guilhem e Diniz (2008), ser ético na pesquisa não significa incorporar as regras de forma incontestável. Na pesquisa social, especialmente a etnográfica, não implica um risco mínimo para os participantes, isto é, ela apresenta apenas um risco semelhante àquele que existe na vida cotidiana - aquele que todos os pais são conscientes que seus filhos correm. O trabalho de investigação etnográfica não se pauta em uso de testes, em grupos de controle e em outras estratégias da pesquisa experimental.

No Brasil, desde os anos de 1980, o debate sobre a questão da ética na pesquisa com crianças já estava presente em publicações dirigidas aos pesquisadores. Nelas eram abordados temas centrais como: consentimento informado, a coerção, as relações de poder entre adultos e crianças, os riscos, os benefícios, o retorno ou a devolução, o uso de imagens, a confidencialidade e os abusos (SPINELLI, 2012).

A publicação da Resolução 196/1996 vem sendo contestada nas ciências humanas e sociais, principalmente pelos antropólogos que têm apresentado suas proposições éticas, em contraponto ao campo da saúde. A ação inicial foi a publicação de um código de ética do antropólogo - não da pesquisa antropológica para que o pesquisador se movesse no campo a partir de balizadores construídos no coletivo. Nele são ressaltados não só os direitos das populações investigadas, mas também guardam a liberdade do pesquisador de formular suas práticas de pesquisa e reivindicar a não censura prévia sobre temas de conflito ou impedimentos para investigar certas populações.

Está claro, para grande parte dos investigadores, que a definição de um código de ética, por meio de uma resolução, possui inúmeros pontos positivos. O primeiro deles foi ter colocado a questão em debate, demonstrando a não- 
neutralidade da pesquisa científica. No entanto, fica evidente que ainda é preciso, no contexto das ciências humanas e sociais, que se pautam por investigações de cunho qualitativo, rever as pesquisas realizadas, as discussões teóricometodológicas por elas implementadas e, pouco a pouco, definir pautas para a discussão. A submissão imediata, aceitando as pautas da pesquisa experimental, apenas empobrecerão a experiência já sistematizada e subordinarão as perspectivas epistemológicas não dominantes. Entretanto, esse é ainda um árduo caminho a ser trilhado, pois a pressão social tem levado os pesquisadores a compreender a resolução como se fosse uma regra burocraticamente necessária e inquestionável.

\section{Mapeamento de questões éticas nas investigações etnográficas com crianças}

Fazer um mapa das tensões éticas pode contribuir para a discussão e tornar possível a formulação de diretrizes para a pesquisa com crianças que tenham um caráter ético, mas que não impeçam a existência de pesquisa etnográfica ou participativa com crianças ou, ainda, que excluam a cidadania do pesquisador ou o protagonismo das populações infantis. Assim, apontam-se três questões consideradas relevantes.

\section{A questão da visão da ciência}

A partir dos anos de 1970, estabelece-se, no cenário internacional, uma grande discussão sobre a hegemonia da pesquisa quantitativa. Vários campos teóricos contrapunham-se ao positivismo hegemônico e problematizaram a hegemonia da pesquisa experimental. Porém, ainda hoje, essa é a principal referência de ciência vigente em grande parte das fundações de apoio à pesquisa e das revistas científicas.

Nesse contexto, a pesquisa qualitativa encontra resistência, pois as comissões de Pesquisa ${ }^{5}$ exigem que o projeto apresente uma metodologia totalmente definida antes da entrada em campo, para que todos os instrumentos sejam avaliados com antecedência, com os roteiros de entrevistas ou de observações, com a população pré-definida, etc. Essa atitude apresenta uma visão burocrática da ética que deve estar presente não apenas no desenho do projeto, mas em todas as fases - desde a concepção até a divulgação dos resultados, a saber: na fase inicial,

\footnotetext{
${ }_{5}^{5}$ A Comissão Nacional de Ética na Pesquisa (CONEP) é uma comissão do Conselho Nacional de Saúde (CNS), criada pela Resolução 196/96, com a função de implementar as normas e diretrizes regulamentadoras de investigações envolvendo seres humanos, aprovadas pelo Conselho. Tem função consultiva, deliberativa, normativa e educativa, atuando conjuntamente com uma rede de Comitês de Ética em Pesquisa (CEP) organizados nas instituições onde as investigações se realizam.
} 
antecipando riscos, refletindo sobre estratégias de consentimento informado; na fase da produção de dados, com a garantia de sigilo (quando necessário, não sendo este uma obrigação) e a não exposição de informantes ou informações, com situações investigativas refletidas; na fase de análise de dados, garantindo a integridade das informações e de seu contexto; no processo de divulgação dos resultados, com controle das informações divulgadas e das omitidas, prevendo acesso amplo ou restrito para elas e criando diferentes possibilidades de devolução para as populações.

Se as pesquisas no campo da saúde exigem, cada vez mais, o cuidado rigoroso dos procedimentos éticos - já que comportam uma imensa desigualdade entre investigadores e investigados e recebem financiamento de diversas origens, inclusive com objetivo de lucro -, e fazem investigações EM seres humanos, a investigação social exige outras formulações éticas, pois trata $\mathbf{C O M}$ os seres humanos em situações bastante diferenciadas (OLIVEIRA, 2004). Mortari (2009) pensa que é primordial saber qual a compreensão de ciência e de pesquisa que é defendida nas investigações, como constatação, com uma lógica de aquisição, que retira as informações e nada restitui, ou se, efetivamente, a investigação é um encontro, uma experiencia transformadora para todos os envolvidos paralelamente à produção de conhecimentos. Para a autora, uma investigação com crianças somente se justifica se aporta algo importante (e bom) PARA as crianças, se melhora a qualidade de suas vidas, se abre novos espaços para ser e viver, isto é, propõe-se uma ação de investigação que seja ética com todos os participantes, como parte de uma ética do cuidado e da responsabilidade. Mesmo quando o tema da investigação não trata de qualquer coisa íntima ou sensível, o fato de participar de uma investigação leva os sujeitos, pesquisadores e pesquisados, a reflexões e a transformações pessoais e sociais, produzindo uma experiência de compartilhamento de ideias ou situações vividas.

Essas ideias são compartilhadas por Alderson (2005), que indaga: que benefícios nós pensamos que esta pesquisa pode trazer para as crianças? Mortari (2007) sugere que podemos tornar a nossa pesquisa mais ética em dois âmbitos: por um lado, no fazer do pesquisador que precisa desenvolver uma atitude específica com essa população, uma forma ética de estar com as crianças; e, por outro lado, no tratamento do material gerado ao fazer a experiência de alteridade, de estar com o outro, pois os dados não são inertes, contêm as vidas dos investigados.

\section{A concepção de infância}

No início da década de 1980, o Brasil dava passos em direção à democracia e à defesa dos direitos de participação política e social das crianças. Naquele 
momento, foi criado um importante movimento da sociedade civil organizada, que defendia a presença de crianças, seu protagonismo e sua autoria. Esse processo alterou os modos de ver as crianças e construiu uma série de perguntas éticas, além da constituição de procedimentos responsáveis para com as crianças: Estávamos usando as crianças quando os acompanhávamos em sua organização social (ex. Movimento dos meninos e meninas de rua)? As crianças podiam ir para as ruas e praças reivindicar seus direitos junto aos adultos? Como documentar esses eventos, poderíamos publicar as imagens dessas crianças? Eram muitas as questões colocadas para a sociedade e, nas respostas, emergiram novas formas de pensar e trabalhar com crianças.

No âmbito internacional, os movimentos pós-Ano Internacional das Crianças (1979) deslocaram o conceito de criança como ser em desenvolvimento, apenas focado na proteção da criança presente na Declaração dos Direitos da Criança (1959) para a transformação em concepções que tencionam e afirmam as possibilidades de participação e protagonismo da Convenção sobre os Direitos da Criança (1989). No Brasil, o principal efeito foi após a Constituição de 1988 com a criação do Estatuto da Criança e do Adolescente (ECA).

Do ponto de vista da investigação com crianças, podemos estabelecer uma analogia entre estes pontos extremos da visão sobre a criança - proteção e participação - e o papel delas na pesquisa. Temos, por um lado, pesquisas em que são feitas análises das produções das crianças, relatórios de observação das crianças com pouca interação pesquisado-pesquisador, investigações de curta duração; e, por outro, modelos que enfatizam a possibilidade de as crianças como sujeitos ativos ao longo de todo o processo de pesquisa, desde a definição dos objetivos, afirmando as crianças como co-pesquisadores (ALDERSON, 2005). As crianças podem, assim, ser envolvidas não só na produção de dados, como informantes, mas podem ser participantes desde o início do planejamento até a abordagem para a análise de dados. Para isso, torna-se impossível o planejamento total da investigação antes do contato com o campo, com as pessoas envolvidas. Afinal as crianças são vistas como sujeitos ativos na contínua produção e na reprodução da vida cotidiana, na cultura infantil e na sociedade (LANGE; MIERENDORFF, 2011). Como afirmam Woodhead e Faulkner (2005, p. 23), mudar a compreensão de uma imagem da criança como ser em desenvolvimento para criança como sujeito participativo não é deixar de levar em conta as diferenças entre adultos e crianças, mas é estabelecer novas responsabilidades de forma a permitir a participação social de forma consistente, com compreensão, interesses e modos de comunicação, especialmente em assuntos que afetam, profundamente, a vida de cada um e do coletivo de crianças. 


\section{Visibilização das crianças - participação e autoria}

A questão da confidencialidade pode representar obstáculos para a divulgação de imagens de crianças, mesmo quando não envolvem qualquer restrição, como em pesquisas sobre temas como a brincadeira ou a leitura - inclusive quando as crianças e os seus responsáveis tenham autorizado. Há uma mística em torno do anonimato dos participantes que torna quase impossível a presença e a autoria das crianças, das escolas, dos professores. Se fazemos pesquisa sobre jogos tradicionais infantis em uma população específica, o registro audiovisual é uma necessidade, uma vez que esses jogos, essas canções e suas coreografias estão em vias de serem perdidos. Registrar essa informação apenas em palavras, sem mostrar o significado presente no movimento dos corpos, dos gestos e dos sorrisos, é perder o conhecimento popular, as culturas infantis. Nessa situação, apresentar o nome da comunidade e publicar os nomes das crianças e dos adultos envolvidos é afirmar a autoria dos grupos sociais e, especificamente, das crianças como sujeitos no mundo. Há toda uma reflexão no campo da antropologia visual, do fotojornalismo, do cinema documental que necessita ser revisitada. As imagens - fotografia, filme, vídeo - são documentos, não são neutros, como qualquer outra modalidade de registro.

As crianças estão no mundo não fora dele. O que importa é perguntar: por que registrar e estudar essas situações? Por que fotografar ou filmar? Nesta pesquisa, importa ou não nomear as crianças? Como narrar a experiência por meio de narrativas visuais éticas? As crianças e os seus responsáveis podem ver e participar da seleção das imagens antes de publicar a pesquisa? Como afirma Butler (2010, p. 96), a regulação do campo visual é um ato de poder. Essas tensões precisam ser discutidas para construirmos uma ética em pesquisa com crianças que possa proteger, mas que também possa mostrar as crianças como sujeitos de direto, com a possibilidade de autoria e participação.

Por fim, uma das funções mais importantes da pesquisa é a sua divulgação. No campo da formação de professores, as imagens feitas pelas crianças e as videogravações dos processos de investigação são instrumentos necessários para refletir sobre a prática pedagógica, para divulgar experiências e sugerir intervenções. Assim, se as pesquisas não permitirem registros audiovisuais, como poderemos transmitir os conhecimentos construídos nas investigações que filmes, fotos e documentos como desenhos, produções escritas podem, com maior clareza, evidenciar? 


\section{Para seguir pensando}

Após o questionamento inicial da concepção hegemônica de ciência, da afirmação da não-neutralidade do pesquisador e da pesquisa, é essencial dizer que laços sociais requerem responsabilidade ética. Construir olhares diferentes para o grupo social infância - bebês e crianças - e as suas instituições de acolhimento é visibilizar e discutir seus direitos de produzir conhecimento, abrir portas para ampliar novas concepções de infância que incluam, também, as ideias de infância das próprias crianças. Estar com significa ser um pesquisador que estuda esses sujeitos, considerados vulneráveis, reconhecendo a importância que os novos coletivos sociais podem aportar para uma visão diferenciada de mundo. Nesse caso, as crianças, especialmente, podem aportar sua possibilidade de renovação do mundo em comum (ARENDT, 2003, p. 247). As pesquisas com crianças podem oferecer um espaço de transformação para os seus interlocutores, que saem da visão das crianças como seres frágeis, incapazes e chegar à visão de que são sujeitos que exigem proteção e cuidado mas que, paradoxalmente, possuem potência.

O pesquisador COM crianças cria espaços solidários e comuns, pois se propõe a ser um adulto que tem uma relação respeitosa com os modos de ser das crianças, que se interessa por elas, pelo que pensam, desenham, escrevem, narram ${ }^{6}$. Pessoas que preferem escutar as crianças para compreendê-las. É uma micro-revolução, constituir com os pequenos uma experiência de capacidade, em vez de falta, de deficiência, como temos feito até agora. A capacidade de pensar e agir das crianças se desenvolve, principalmente, em um mundo que as escuta. Escutar as crianças não é tarefa fácil. Como converter a voz das crianças em uma voz que pode ser escutada? Em uma voz que conte, uma voz capaz de articular um desejo, de afirmar um poder, de articular uma nova linguagem ou inclusive de produzir uma nova língua, ou até mesmo um novo vocabulário para o viver, de transformar a língua do poder? (BUTLER, 2010). Redefinir os códigos éticos, passando de uma versão moralizadora de pesquisa para uma ética de pesquisa com as crianças é uma tarefa geracional que precisamos enfrentar para que a ciência não só constate mas produza compreensão e transformação nos modos de produzir infâncias, as culturas infantis e afirmar o empoderamento das crianças.

\footnotetext{
${ }^{6} \mathrm{~A}$ ética de um investigador que tenha respeito, se sinta responsável, ofereça experiências positivas, dê tempo às crianças e não roube seu tempo, isto é, ser receptivo, responsivo, atento, disponível, sem ser intrusivo, tendo a atenção ao clima emocional e, mantendo a serenidade para estabelecer uma relação de confiança com os meninos e as meninas participantes dos projetos de pesquisa.
} 


\section{Referências}

ALDERSON, P. As crianças como pesquisadores: os efeitos dos direitos de participação sobre a metodologia de pesquisa. Educação \& Sociedade, Campinas, v. 26, n. 91, p. 419442. maio/ago. 2005. DOI: 10.1590/S0101-73302005000200007

ARENDT, H. Entre o passado e o futuro. São Paulo: Perspectiva, 2003.

BRASIL. Ministério da Saúde/Conselho Nacional de Saúde. Resolução 196/1996. Diretrizes e normas regulamentadoras de pesquisas envolvendo seres humanos. Brasília, 10 out. 1996.

BRASIL. Ministério da Saúde/Conselho Nacional de Saúde. Resolução 466/2012. Diretrizes e normas regulamentadoras de pesquisas envolvendo seres humanos. Brasília, 12 dez. 2012.

BUTLER, J. Marcos de Guerra. Las vidas lloradas. Madrid, Espanha: Espasa, 2010.

CHRISTENSEN, P.; JAMES, A. Research with children: perspectives and practices. London, Falmer Press, 2000.

GRAUE, M. E.; WALSH, D. J.; CHAVES, A. M. Investigação etnográfica com crianças: teorias, métodos e ética. Lisboa: Fundação Calouste Gulbenkian, 2003.

GUILHEM, D.; DINIZ, D. O que é ética na pesquisa. São Paulo: Brasiliense, 2008.

LANGE, A.; MIERENDORFF, J. Method and methodology in childhood research. In: QVORTRUP, J.; CORSARO, W.; HONIG, M. S. The Palgrave Handbook of Childhood Studies. London: Palgrave Macmillan, 2011. p. 78-95.

MORTARI, L. Cultura dela ricerca e pedagogia. Roma: Carocci, 2007.

MORTARI, L. La ricerca PER i bambini. Milano, Italy: Mondadori, 2009.

OLIVEIRA, R. C. O mal-estar da ética na antropologia prática. In: VICTORA, C. Antropologia e ética: o debate atual no Brasil. Niterói: Universidade Federal Fluminense, 2004. p. 21-32.

QVORTRUP, J.; CORSARO, W.; HONIG, M. S. The Palgrave Handbook of Childhood Studies. London: Palgrave Macmillan, 2011.

SILVA, A.; MACEDO, A. V. L. S.; NUNES, A. Introdução. In: SILVA, A. L.; MACEDO, A. V. L. S.; NUNES, A. Crianças indígenas: ensaios antropológicos. São Paulo: MARE; FAPESP; Global, 2002.

SPINELLI, C. S. As metodologias de pesquisa com crianças na escola: o ouvir como tendência. 2012. 333 f. Dissertação (Mestrado em Educação) - Universidade Federal de Santa Catarina, Florianópolis, 2012.

WOODHEAD, M.; FAULKNER, D. Sujeitos, objectos ou participantes? Dilemas da investigação psicológica com crianças. In: CHRISTENSEN, P.; ALLISON, J. (Orgs.). Investigação com crianças: perspectivas e práticas. Porto: ESEPF, 2005.

Recebido em 01/02/2014

Versão final recebida em 10/03/2014

Aceito em 17/03/2014 